\title{
Modul DAN KeUJudAn Basis PAdA MOdul BeBAS
}

\section{MODULES AND BASES OF FREE MODULES}

\author{
Dian Mardiani \\ Pendidikan Matematika, STKIP Garut \\ Garut, Indonesia \\ Alfid51@yahoo.com
}

\begin{abstract}
Abstrak
Penelitian ini membahas beberapa sifat bagi modul. Modul merupakan perluasan dari ruang vektor. Sebarang ruang vektor $V$ atas lapangan $F$, dapat dipandang sebagai modul atas gelanggang $F$. Tetapi tidak semua sifat di ruang vektor dapat berlaku pada modul. Kontribusi utama yang dihasilkan penelitian ini adalah kajian pustaka tentang beberapa pengertian dan sifat pada modul. Dapat disimpulkan bahwa setiap ruang vektor adalah modul, tetapi tidak setiap modul adalah ruang vektor. Modul atas gelanggang yang bukan lapangan bukanlah ruang vektor. Berdasarkan keujudan basis, modul dikategorikan ke dalam modul bebas dan modul tak bebas.
\end{abstract}

Kata Kunci: modul, modul bebas, ruang vektor.

\begin{abstract}
This project studies about properties of modules. Modules is an extension of a vector space. A vector space is a module over a field. Many of the basic concepts that we defined for vector spaces can also be defined for modules. The main contribution is studies about definition and properties of modules. These include every vector space is modules, but many of modules is vector space. Modules over ring is not vector space, because ring is not a field. There are free modules and not free modules. If the modules has basic, it is free modules.
\end{abstract}

Keyword: modules, free modules, vector space.

\section{Pendahuluan}

Modul merupakan perluasan dari ruang vektor. Sebarang ruang vektor $\mathrm{V}$ atas lapangan F, dapat dipandang sebagai modul atas gelanggang F. Tetapi tidak semua sifat di ruang vektor dapat berlaku pada modul.

Pada pengkajian ruang vektor, ada pengertian subruang. Di ruang vektor suatu subruang, B dikatakan suatu basis bagi ruang vektor $\mathrm{V}$ jika $\mathrm{B}$ bebas linier di $\mathrm{V}$ dan membangun V. Setiap ruang vektor yang tak kosong selalu memiliki basis. Ternyata pada modul, sifat ini juga berlaku.
Ada beberapa sifat ruang vektor yang berlaku pada modul, Proyek ini bertujuan untuk mengkaji apakah pengertian dan sifat sekitar modul? Ini merupakan penelitian kajian pustaka. Pada Bab II akan dituliskan beberapa sifat dasar gelanggang dan daerah ideal utama. Hasil penelitian akan dipaparkan di Bab III. Bab III merupakan inti dari proyek ini. Pada bab ini akan diketengahkan beberapa pengertian dan sifat sekitar modul. Pada Bab IV akan dituliskan kesimpulan tentang pengertian dan sifat sekitar modul dan keujudan basis dalam modul bebas. 


\section{KAJIAN TEORI}

Tulisan ini merupakan suatu kajian pustaka. Diawali dengan mengkaji definisi dan sifat-sifat gelanggang.

Pada bab ini akan dipaparkan pengertian gelanggang, lapangan, daerah integral, dan daerah ideal utama. Pengertian gelanggang sangat penting dituliskan pada bab ini karena modul tumpuannya merupakan gelanggang.lebih khusus ada modul yang tumpuannya merupakan gelanggang yang merupakan daerah ideal utama. Dapat dilihat bahwa setiap daerah ideal utama adalah daerah integral, tetapi tidak setiap daerah integral merupakan daerah ideal utama. Pembahasan tentang ideal dapat ditemukan dalam Arifin [1].

\section{Definisi 2.1}

Misalkan $R$ suatu himpunan tak kosong dan + serta $\cdot$ adalah operasi di $R$.

$$
\begin{aligned}
+: \quad R \times R \rightarrow R & \text { dan } \quad:: \quad R \times R \rightarrow R \\
(a, b) & \mapsto a+b
\end{aligned}
$$

yang berturut-turut disebut operasi tambah dan operasi kali. Sistem matematika $(R,+, \cdot) \quad$ disebut gelanggang jika memenuhi aksioma-aksioma berikut:

A. Sistem matematika $(R,+)$ membentuk grup abel, yaitu:

1. untuk setiap $a, b, c \in R$ berlaku $(a+b)+c=a+(b+c)$,

2. terdapat unsur identitas $u \in R$ yang bersifat $a+u=u+a=a$, untuk setiap $a \in R$,

3. untuk setiap $a \in R$, terdapat $b \in R$ sehingga $a+b=b+a=u$,

4. untuk setiap $a, b \in R, a+b=$ $b+a$.

B. Sistem matematika $(R, \cdot)$ membentuk monoid, yaitu:
1. untuk setiap $a, b, c \in R$ berlaku

$$
(a \cdot b) \cdot c=a \cdot(b \cdot c) \text {, }
$$

2. terdapat unsur identitas $e \in R, e \neq$ $u$, sehingga $a . e=e \cdot a=a$, untuk setiap $a \in R$.

C. Sistem matematika $(R,+, \cdot)$ bersifat distributif, untuk setiap $a, b, c \in R$ berlaku $(a+b) \cdot c=a \cdot c+b \cdot c$ dan $c \cdot n(a+b)=c \cdot a+c \cdot b$.

Dalam pembicaraan selanjutnya gelanggang $(R,+, \cdot)$ dinotasikan dengan $R$. Unsur $u$ dalam definisi diatas disebut unsur nol dan diberi notasi 0. Kemudian unsur balikan dari $a \in R$ disebut negatif dari $a$ dan dinotasikan dengan $-a$. Unsur identitas terhadap operasi kali yaitu $e$ pada definisi di atas disebut unsur kesatuan dan diberi notasi angka 1 [2].

\section{Definisi 2.2}

Misalkan $R$ suatu sistem matematika dengan operasi tambah dan kali. Sistem $R$ disebut gelanggang komutatif jika $R$ gelanggang dan untuk setiap $a, b \in$ $R$ berlaku $a \cdot b=b \cdot a$.

Sistem bilangan real $\mathbb{R}$ dan sistem bilangan bulat $\mathbb{Z}$ merupakan gelanggang komutatif.

\section{Definisi 2.3}

Misalkan $R$ suatu sistem matematika dengan operasi tambah dan kali. Sistem $R$ disebut lapangan jika $R$ membentuk gelanggang komutatif dan setiap unsur tak nolnya merupakan unit, yaitu untuk setiap $a \in R$ dengan $a \neq 0$ terdapat $b \in R$ sehingga $a b=b a=1$.

Sistem bilangan real $\mathbb{R}$ merupakan lapangan.Tetapi sistem bilangan bulat $\mathbb{Z}$ bukan lapangan, karena ada unsur tak nol di $\mathbb{Z}$ yaitu 2 yang bukan unit. 


\section{Definisi 2.4}

Suatu sistem matematika $(R,+, \cdot)$ disebut daerah integral jika $R$ membentuk gelanggang komutatif dan untuk setiap $a, b \in R$ berlaku jika $a b=0$ maka $a=0$ atau $b=0$.

Sistem bilangan real $\mathbb{R}$ dan sistem bilangan bulat $\mathbb{Z}$ merupakan daerah integral. Sistem bilangan bulat $\mathbb{Z}$ merupakan daerah integral tetapi bukan lapangan. Ini dapat dijadikan bukti bahwa tidak setiap daerah integral adalah lapangan. Namun dapat ditunjukkan bahwa setiap lapangan merupakan daerah integral.

\section{Teorema 2.1}

Setiap lapangan merupakan suatu daerah integral.

\section{Bukti.}

Misalkan $H=(H,+,$.$) lapangan maka$ untuk setiap $a \in H \backslash\{0\}$, terdapat $a^{-1} \in H$ sehingga $\quad a^{-1} a=a a^{-1}=1$. Untuk membuktikan bahwa $(H,+,$.$) suatu$ daerah integral harus ditunjukkan bahwa untuk setiap $a, b \in H$ berlaku jika $a b=$ 0 maka $a=0$ atau $b=0$. Ambil sebarang $a, b \in H$ dengan $a b=0$. Jika $a \neq 0$, maka terdapat $a^{-1} \in H$ sehingga $a^{-1} a=$ $a a^{-1}=1$. Perhatikan fakta bahwa $1+0=1$. Jika kedua ruas dikalikan dengan $a^{-1} \quad$ maka diperoleh $a^{-1}(1+0)=a^{-1}$. Ini ekivalen dengan $a^{-1}+$ $a^{-1} \cdot 0=a^{-1}$. Artinya $a^{-1} \cdot 0=0$. Karena $=0$, maka $a^{-1}(a b)=a^{-1} 0=0$. Dengan demikian $\quad\left(a^{-1} a\right) b=1 b=b=0$. Jadi jika $a b=0$ dan $a \neq 0$ maka $b=0$.

Misalkan untuk setiap $a, b, c \in H, a \neq$ 0 berlaku jika $a b=a c$ maka $b=c$ dapat dikatakan pada $H$ berlaku hukum pembatalan kiri. Hukum pembatalan kanan dapat didefinisikan serupa.

\section{Teorema 2.2}

$D$ daerah integral jika dan hanya jika $D$ ring komutatif dan berlaku hukum pembatalan kiri/kanan.

\section{Bukti:}

Misalkan $D$ daerah integral maka $D$ ring komutatif. Ambil sebarang $a, b, c \in D$ dengan $a b=a c$ dan $\quad a \neq 0 \quad$ maka $a b-a c=0$, bentuk persamaan ini ekivalen dengan $a(b-c)=0$. Karena $a \neq 0$ dan $D$ daerah integral maka $b-c=0$. Akibatnya $b=c$.

Misalkan $D$ ring komutatif dan di $D$ berlaku hukum pembatalan kiri. Ambil sembarang $a, b \in D$ dengan $a b=0$. Jika $a \neq 0$ maka $a b=0=a 0$. Karena hukum pembatalan kiri berlaku di Dmaka diperoleh $b=0$.

Sebarang daerah integral belum tentu merupakan lapangan, tetapi sebarang daerah integral yang memiliki berhingga unsur adalah lapangan. Untuk membuktikan sifat tersebut akan ditunjukkan terlebih dahulu bahwa jika $D$ daerah integral dengan berhingga unsur dan $h: D \rightarrow D$ fungsi satu-satu maka $h$ fungsi pada.

\section{Definisi 2.5}

Misalkan ada dua himpunan $A$ dan $B$. Misalkan pula ada fungsi $h$ yang memetakan setiap unsur di $A$ ke unsur di $B$. Himpunan peta dari $A$ dinotasikan $\{h(a) \mid a \in A\} . \quad$ Ini merupakan subhimpunan dari $B$ dan disebut

range $(h)$.

\section{Teorema 2.3}

Jika D himpunan berhingga dan $h: D \rightarrow$ $D$ fungsi satu-satu maka $h$ fungsi pada. 
Bukti.

Teorema 2.3 ini akan dibuktikan dengan menunjukkan bahwa range $(h) \subseteq D$ danbanyaknya unsur di $D$, sama dengan banyaknya unsur di range $(h)$. Berdasar definisinya, jelas Range $(h) \subseteq D$. Karena h fungsi satu-satu makah $(a) \neq h(b)$ untuk setiap $a \neq b$. Akibatnya banyaknya unsur di $D$ sama dengan banyaknya anggota himpunan $\quad\{h(a) \mid a \in D\} . \quad$ Artinya banyaknya unsur di $D$ sama dengan banyaknya unsur di range $(h)$.Jadi $h$ fungsi pada.

Selanjutnya dapat dilihat bahwa daerah integral yang berhingga merupakan lapangan.

\section{Teorema 2.4}

Jika $D$ daerah integral yang berhingga maka D lapangan.

\section{Bukti.}

Misalkan $D=(D,+,$.$) daerah integral$ hingga. Akan ditunjukkan bahwa $D$ suatu lapangan dengan menunjukkan untuk setiapa $\in D \backslash\{0\}$, terdapat $b \in D$ sehingga $a b=b a=1$.Untuk itu dibuat suatu pemetaanh: $D \rightarrow D$ yang didefinisikan oleh $h(x)=a x$, untuk suatu $x \in D$.

Ambil sembarang $x, y \in D \quad$ sehingga $h(x)=h(y) \quad$ maka $a x=a y . \quad$ Karena $a \neq 0$ dan $D$ daerah integral maka berlaku hukum pembatalan sehingga $x=y$. Jadi $h$ merupakan fungsi satu-satu. Menurut Teorema 2.3 hal ini mengakibatkan $h$ merupakan fungsi pada. Karena $h$ fungsi pada maka untuk setiap $z \in D$, terdapat $w \in D$ sehingga $h(w)=a w=z$. Untuk $z=1$, terdapat $b \in D$ sehingga $h(b)=$ $a b=1$. Jadi terdapat $b \in D$ sehingga $a b=1$ untuk setiap $a \in \mathrm{D} \backslash\{0\} . \quad$ Jadi $D$ lapangan.

Pengertian daerah ideal utama sangat penting karena tulisan ini bertujuan untuk menyelidiki sifat dari modul atas daerah ideal utama. Sebelum membahas mengenai daerah ideal utama, akan dibahas terlebih dahulu pengertian ideal.

\section{Definisi 2.6}

Misalkan I suatu subhimpunan tak hampa dari gelanggang $R$. Maka $I$ suatu ideal jika dan hanya jika untuk setiap unsur $x$ dan $y$ di $I$ dan $r \in R$ berlaku $x+y \in I$ dan $r x \in I$.

Pada sistem bilangan bulat, $5 \mathbb{Z}$ adalah himpunan yang merupakan ideal di $\mathbb{Z}$. Karena setiap anggota $\mathbb{Z}$ jika dikalikan dengan anggota5Z akan merupakan anggota $5 \mathbb{Z}$. Ideal $5 \mathbb{Z}$ dibangun oleh satu unsur di $5 \mathbb{Z}$ yaitu 5 . Karena itu, dapat dituliskan $5 \mathbb{Z}=\langle 5\rangle$. Artinya $5 \mathbb{Z}$ adalah ideal yang dibangun oleh satu unsur.

\section{Definisi 2.7}

Misalkan $R$ daerah integral dan $I$ suatu ideal di $R$. Ideal $I$ dikatakan ideal utama di $R$ jika terdapat $a \in I$ sehingga $I=\langle a\rangle$.

Karena sifatnya yang dibangun oleh satu unsur, $5 \mathbb{Z}$ adalah suatu ideal utama di $\mathbb{Z}$. Dapat dilihat pula bahwa setiap $a \mathbb{Z}$ dengan $a \in a \mathbb{Z}$ adalah suatu ideal utama di $\mathbb{Z}$. Beberapa daerah integral memiliki sifatbahwa setiap idealnya merupakan ideal utama, sehingga dapat dibangun pengertian daerah integral yang memenuhi sifat tersebut.

\section{Definisi 2.8}

Misalkan $R$ daerah integral dan setiap ideal di $R$ merupakan ideal utama maka $R$ disebut daerah ideal utama. 
Sistem bilangan bulat $\mathbb{Z}$ adalah daerah ideal utama, karena setiap ideal di $\mathbb{Z}$ di bangun oleh satu unsur [2]. Pada bab berikutnya akan dibahas tentang pengertian modul atas gelanggang. Akan dibahas juga modul atas daerah ideal utama, modul torsi, modul primer dan modul yang dibangun secara hingga.

\section{PeMbahasan}

Pada bab ini akan dijelaskan beberapa pengertian dan sifat modul. Akan diketengahkan pada bab ini bahwa setiap ruang vektor adalah modul tetapi tidak setiap modul merupakan ruang vektor. Berdasarkan keujudan basis, modul dikategorikan ke dalam modul bebas dan modul tidak bebas. Dijelaskan pula di bab ini mengenai pengertian modul yang dibangun secara hingga.

\section{Definisi 3.1}

Modul $M$ atas gelanggang komutatif $R$ atau $R$-modul adalah sistem matematika $(M,+)$ yang dilengkapi dengan operasi skalar

$$
\begin{aligned}
& \because R \times M \rightarrow M \\
& (\alpha, x) \quad \mapsto \alpha x
\end{aligned}
$$

yang memenuhi sifat

1. $(M,+)$ membentuk grup komutatif

2. Untuk setiap $r$ dan $s$ di $R \operatorname{serta} u$ dan $v$ di Mberlaku:
a) $r(u+v)=r u+r v$
b) $(r+s) u=r u+s u$
c) $(r s) u=r(s u)$
d) $1 u=u$.

Ruang vektor atas lapangan adalah modul atas lapangan. Jika $R$ gelanggang, $R^{n}$ adalah modul atas $R$. Semua gelanggang komutatif dengan unsur kesatuan adalah modul. Pada ruang vektor dikenal pengertian subruang, demikian pula di teori modul, terdapat pengertian submodul [3]. Pembahasan tentang modul atas gelanggang, dapat ditemukan dalam Arifin [1].

\section{Definisi 3.2}

Suatu submodul dari $R$-modul $M$ adalah subhimpunan $S$ yang tak kosong dari $M$ yang merupakan $R$-modul dibawah operasi yang sama di $M$.

Pandang $\mathbb{Z}$ sebagai $\mathbb{Z}$-modul, maka $\langle 3\rangle$ adalah submodul dari $\mathbb{Z}$. Untuk menunjukkan $\langle 3\rangle$ adalah submodul dari $\mathbb{Z}$, dapat digunakan sifat berikut ini.

\section{Teorema 3.1}

Misalkan S subhimpunan tak kosong dari R-modul M. HimpunanS dikatakan submodul dari $M$ jika dan hanya jika $S$ tertutup terhadap kombinasi linier berikut. Jika $r, s \in R, u, v \in S$ maka $r u+s v \in S$.

Bukti.

Ambil sembarang $r, s \in R, u, v \in S$. Karena $S$ submodul dari $M$ maka $r u \in S$ dan $s v \in S$.Jadi $r u+s v \in S$.

Misalkan $r u+s v \in S$ untuk setiap $r, s \in R, u, v \in S$. Akan dibuktikan $S$ submodul dari $M$. Pandang1 $=1+0$. Jika kedua ruas kita kalikan dengan $v$ akan diperoleh $v=v+0 v$ sehingga $0 v=0$. Pandang $\quad 1+(-1)=0$. Dapat ditunjukkan bahwa $-1 v=v$. Selanjutnya ambil sembarang $u, v \in S, \alpha \in R$. Pilih $s=0$, maka akan diperoleh $r u+s v=$ $r u+0 . v=r u \in S$. Ambil sembarang $u, v \in S$.Pilih $r=s=1$ maka $r u+s v=$ 1. $u+1 . v=u+v \in S$. Berikutnya ambil sembarang $u, v \in S . \quad$ Pilih $r=1$ dan $s=-1$ maka diperoleh $r u+s v=1 . u+$ $(-1) \cdot v=u-v \in S$. Ambil sembarang 
$r, s \in R, u, v \in S$. Karena $S$ subhimpunan dari $M$ maka $u, v \in M$. Karena $M$ modul atas gelanggang $R$ maka berlaku $r(u+$ $v)=r u+r v,(r+s) u=r u+$ $s u,(r s) u=r(s u)$, dan $1 u=u$.Jadi $S$ submodul dari $M$.

Jika ada dua himpunan yang merupakan submodul dari $R$-modul $M$ maka dapat ditunjukkan bahwa irisan dua himpunan tersebut merupakan submodul dari $R$ modul $M$. Selain itu, misalkan $A$ dan $B$ dua himpunan submodul dari $M$, maka $A+B=\{a+b \mid a \in A$ dan $b \in B\} \quad$ juga submodul dari $M$.

\section{Teorema 3.2}

Misalkan S dan T submodul dari R-modul M.S $\cap T$ dan $S+$ Tmerupakan submodul dari R-modul $M$.

\section{Bukti.}

Misalkan $S$ dan $T$ submodul dari $R$-modul $M$. Ambil sembarang $r, p$ di $R$ dan $u, v$ di $S \cap T$. Karena $u, v$ di $S \cap T$ maka $u, v \in$ $S$ dan $u, v \in T$. Karena $S$ dan $T$ submodul dari $M$ maka $r u+p v \in S$ dan $r u+p v \in$ $T$. Artinya $r u+p v \in S \cap T$. Jadi $S \cap$ $T$ submodul dari $R$-modul $M$.

Ambil sembarang $u, v \in S+T, r, p \in R$. Tulis $u=s_{1}+t_{1}$, dengan $s_{1} \in S$ dan $t_{1} \in T$, dan $v=s_{2}+t_{2}$, dengan $s_{2} \in S$ dan $t_{2} \in T$.Maka diperoleh $r u+p v=$ $r\left(s_{1}+t_{1}\right)+\mathrm{p}\left(s_{2}+t_{2}\right)=r s_{1}+r t_{1}+p s_{2}+$ $p t_{2} \in S+T$. Jadi $S+T$ submodul dari $R$ modul $M$.

Pandang gelanggang komutatif dengan unsur identitas $R$ sebagai modul atas dirinya sendiri. Modul $R$ atas $R$ membawa implikasi penting. Jika $S$ adalah submodul dari $R$, maka $S$ tertutup terhadap perkalian dengan semua anggota $R$, artinya $S$ sebuah ideal dari gelanggang $R$. Jadi submodul dari $R$-modul $R$ adalah ideal dari gelanggang $R$.

Setiap modul memiliki pembangun. Setidaknya pembangun dari $M$ adalah $M$ sendiri. Tetapi tidak semua pembangun dari $M$ berhingga. Pada ruang vektor berdimensi hingga berlaku setiap subruangnya juga berdimensi hingga. Tetapi pada modul tidak demikian. Misalkan $F\left[x_{1}, x_{2}, \ldots\right]$ adalah himpunan polinom dengan tak hingga variabel. Himpunan ini dapat dipandang sebagai modul atas dirinya sendiri yang dibangun oleh pembangun berhingga, yaitu $\langle 1\rangle$. Tetapi himpunan ini memiliki subhimpunan yang dibangun oleh pembangun tak hingga $\left\langle x_{1}, x_{2}, \ldots\right\rangle$ yaitusubhimpunan dengan konstanta sama dengan nol, $\quad P=\left\{p(x) \mid a_{0}=\right.$ 0 , untuk setiap $\left.p(x) \in F\left[x_{1}, x_{2}, \ldots\right]\right\}$.

\section{Definisi 3.3}

Misalkan $B$ subhimpunan tak kosong dari $R$-modul $M$. Himpunan $B$ dikatakan membangun $M$ jika setiap unsur di $M$ dapat dinyatakan sebagai kombinasi linier dari unsur-unsur di $B$.

Pandang $\mathbb{Z}^{3}$ sebagai modul atas $\mathbb{Z}$. Pembagun dari modul tersebut adalah $\left\{\left(\begin{array}{l}1 \\ 0 \\ 0\end{array}\right),\left(\begin{array}{l}0 \\ 1 \\ 0\end{array}\right),\left(\begin{array}{l}0 \\ 0 \\ 1\end{array}\right)\right\}$. Pembangun dari suatu modul dapat saja berupa himpunan yang terdiri atas satu unsur. Modul yang dibangun oleh satu unsur disebut modul siklik.

\section{Definisi 3.4}

Misalkan $S$ submodul dari $R$-modul $M$. Submodul $S$ dikatakan submodul siklik 
di $M$ jika terdapat $v \in M$ sehingga $S=\langle v\rangle=R v$.

Pandang $\mathbb{Z}$ sebagai $\mathbb{Z}-$ modul, maka3Z merupakan submodul siklik di $\mathbb{Z}$. Dapat ditunjukkan bahwa $3 \mathbb{Z}=\langle 3\rangle$.

Modul atas daerah ideal utama $\mathbb{Z}$ merupakan $D$-modul. Pada tulisan ini akan dikaji tentang modul yang dibangun secara hingga. Karena itu, perlu dipahami pengertian modul yang dibangun secara hingga.

\section{Definisi 3.5}

Misalkan $M$ adalah $R-$ modul. Modul $M$ dikatakan dibangun secara hingga jika dan hanya jika terdapat $A=$ $\left\{a_{1}, \ldots, a_{n}\right\}$ subhimpunan tak kosong dari $M$, sehingga untuk setiap $m \in M$, berlaku $m=\sum_{i=1}^{n} r_{i} a_{i}$ untuk suatu $r_{1}, \ldots, r_{n} \in R$.

Jadi $M$ dibangun secara hingga berarti pembangun dari $M$ adalah himpunan berhingga. Setiap ruang vektor tak nol, adalah modul atas lapangan yang dibangun secara hingga oleh himpunan yang merupakan basisnya.

Pada ruang vektor dikenal pengertian bebas linier. Pada modul, pengertian bebas linier diperluas menjadi pengertian bebas. Pada ruang vektor $V$, tidak sulit untuk menunjukkan bahwa subhimpunan yang bebas di $V$ adalah bebas linier. Karena setiap modul selalu memiliki pembangun, maka jika pembangunnya bebas di modul tersebut, maka dikatakan modul ini memiliki basis. Modul dapat dikategorikan menjadi modul yang memiliki basis dan yang tidak memiliki basis. Modul yang memiliki basis diebut modul bebas.

Definisi 3.6

Misalkan $\quad B=\left\{b_{1}, b_{2}, \ldots, b_{n}\right\}$ subhimpunan dari ruang vektor $V$.
Subhimpunan B dikatakan bebas linier jika $0=\sum_{i=1}^{n} \alpha_{i} b_{i}$, hanya dipenuhi oleh $\alpha_{i}=0$.

\section{Definisi 3.7}

Misalkan $M$ suatu $R$-modul. $M$ dikatakan modul bebas jika $M=\{0\}$ atau $M$ memiliki basis.

Sistem bilangan bulat $\mathbb{Z}$ suatu $\mathbb{Z}$ - modul, memiliki basis $\{1\}$. Himpunan $\mathbb{Z}^{2}$ modul atas $\mathbb{Z}$ memiliki basis $B=\left\{\left(\begin{array}{l}1 \\ 0\end{array}\right),\left(\begin{array}{l}0 \\ 1\end{array}\right)\right\}$. Karena memiliki basis, kedua modul tersebut merupakan modul bebas.

Himpunan $\mathbb{Z}_{n}$ atas $\mathbb{Z}$ bukan merupakan modul bebas.

Bukti.

Terlebih dahulu akan dibuktikan bahwa misalkan $X=\left\{x_{1}, x_{2}, \ldots, x_{n}\right\}$ subhimpunan dari $R$-modul $M$ bergantung linier maka $X \cup\{v\}$ dengan $v \in M \backslash X \quad$ juga bergantung linier. Pandang kombinasi linier $0=\sum_{i=1}^{n} r_{i} x_{i}+p v$, untuk suatu $r_{i}, p \in R$.

\section{Kasus 1:}

Jika $p \neq 0$, maka terdapat skalar tak nol yang memenuhi kombinasi linier $0=$ $\sum_{i=1}^{n} r_{i} x_{i}+p v, \quad$ artinya $\quad X \cup\{v\}$ bergantung linier.

\section{Kasus 2:}

Jika $p=0$ maka $0=\sum_{i=1}^{n} r_{i} x_{i}$

Karena $X$ bergantung linier maka terdapat $r_{i} \neq 0, \quad$ untuk suatu $i \in\{0,1, \ldots, n\}$ sehingga memenuhi kombinasi linier $0=\sum_{i=1}^{n} r_{i} x_{i}+p v, \quad \quad \operatorname{artinya} X \cup$ $\{v\}$ bergantung linier.

Jadi jika $X$ bergantung linier maka $X \cup\{v\}$ juga bergantung linier. Selanjutnya akan dibuktikan bahwa $Z_{n}$ bukan modul bebas. Ambil sebarang $\{\bar{a}\} \subseteq Z_{n}, \quad \operatorname{maka} \overline{0}=0 . \bar{a} \quad$ dan $\quad \overline{0}=n \cdot \bar{a}$. 
Artinya setiap subhimpunan dari $Z_{n}$ yang memuat satu unsur tidak bebas linier, sehingga $Z_{n}$ tidak memiliki subhimpunan yang bebas linier. Artinya $Z_{n}$ bukan modul bebas.

\section{Teorema 3.3}

Misalkan $M \quad$ suatu $R$-modul, $B$ subhimpunan dari $M$ adalah basis bagi Mjika dan hanya jika untuk setiap $v \in M, v$ merupakan kombinasi linier dari vektor-vektor di B secara tunggal.

\section{Bukti.}

Misalkan $B=\left\{b_{i}\right\}_{i \in I}$ basis dari $R-$ modul $M$ yang dibangun secara hingga. Ambil sebarang $v \in M$. Misalkan $v=$ $\sum_{i \in I} \alpha_{i} b_{i} \quad$ dan $\quad v=\sum_{i \in I} \beta_{i} b_{i} . \quad$ Maka $\sum_{i \in I} \alpha_{i} b_{i}-\sum_{i \in I} \beta_{i} b_{i}=0 \quad$ artinya $\sum_{i \in I}\left(\alpha_{i}-\beta_{i}\right) b_{i}=0$. Karena $B$ bebas linier di $M$ maka kombinasi linier ini hanya dipenuhi oleh $\alpha_{i}-\beta_{i}=0$, jadi $\alpha_{i}=\beta_{i}, i \in I$.

Misalkan untuk setiap $v \in M, \quad v$ merupakan kombinasi linier dari vektorvektor di $B$ secara tunggal. Pandang kombinasi linier $0=\sum_{i \in I} \alpha_{i} b_{i}$ untuk suatu $\alpha_{i} \in R$. Diketahui $0=\sum_{i \in I} 0 . b_{i}$. Karena $0 \in M$ maka kombinasi linier $0=$ $\sum_{i \in I} \alpha_{i} b_{i}$ hanya dipenuhi oleh $\alpha_{i}=0$, untuk setiap $i \in R$.Jadi $B$ bebas linier di $M$. Karena $B$ membangun $M$ dan bebas linier di $M$ maka $B$ basis bagi $M$.

Pada ruang vektor $V$ berlaku jika $X$ basis $V$, maka $X$ membangun minimal dan $X$ bebas linier maksimal. Ternyata sifat ini berlaku pula pada modul.

\section{Teorema 3.4}

Misalkan $M$ suatu $R$-modul. Jika $B$ basis $M$ maka $B$ membangun minimal dan $B$ bebas linier maksimal.
Bukti.

Misalkan $B=\left\{b_{i}\right\}_{i \in I}$ basis bagi $R-$ modul $M$. Ambil sembarang $b \in B$. Andaikan $B-b$ membangun $M$ maka untuk setiap $v \in M, v=\sum_{\substack{i \in I \\ b_{i} \neq b}} r_{i} b_{i}$ untuk suatu $r_{i} \in R$ dengan $r_{i}$ hampir semua nol.Karena $b \in B$ maka $b \in M$, akibatnya $b=\sum_{\substack{i \in I \\ b_{i} \neq b}} r_{i} b_{i}$ untuk suatu $r_{i} \in R$ dengan $r_{i}$ hampir semua nol. Ini mengakibatkan $\sum_{\substack{i \in I \\ b_{i} \neq b}} r_{i} b_{i}-b=0$ artinya terdapat skalar tak nol yaitu -1 yang menyebabkan $\sum_{\substack{i \in I \\ b_{i} \neq b}} r_{i} b_{i}=0, \quad$ sehingga $B$ bergantung linier. Ini kontradiksi dengan $B$ basis dari $M$. Jadi pengandaian salah. Haruslah $B$ membangun minimal.

Misalkan $B=\left\{b_{i}\right\}_{i \in I}$ basis bagi Rmodul M. ambil sebarang $v \in M \backslash B$, karena $B$ membangun $M$ maka $v=$ $\sum_{i \in I} r_{i} b_{i}$ untuk suatu $r_{i} \in R$ dengan $r_{i}$ hampir semua nol. Karena itu $\sum_{i \in I} r_{i} b_{i}-$ $v=0$. Ini berarti terdapat skalar tak nol yaitu -1 sehingga $\sum_{i \in I} r_{i} b_{i}+p v=0 . J a d i$ $B \cup\{v\}$ bergantung linier untuk setiap $v \in M \backslash B$. Jadi B bebas linier maksimum.

\section{Penutup}

Setiap ruang vektor adalah modul, tetapi tidak setiap modul adalah ruang vektor. Ruang vektor atas lapangan merupakan modul atas lapangan. Setiap lapangan adalah gelanggang, maka jika modul atas gelanggang yang bukan lapangan, maka modul tersebut bukan ruang vektor. Berdasarkan keujudan basis, modul dikategorikan ke dalam modul 
bebas dan modul tak bebas. Modul bebas adalah modul yang memiliki basis.

\section{DAfTAR PUstaka}

[1] A. Arifin, Aljabar. ITB, 2000.

[2] A. Muchlis dan P. Astuti, Aljabar I, Edisi 1, Universitas Terbuka, 2007.

[3] S. Roman, Advanced linear algebra, 3rd. Ed., Springer-Verlag, 1992.

\section{Riwayat Hidup PenUlis}

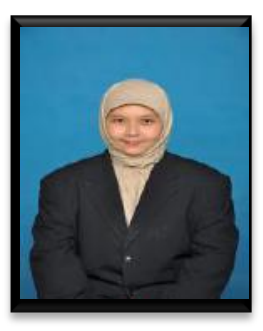

Dian Mardiani, M. PMat. Lahir di Garut, 30 Oktober 1978.Staf pengajar di STKIP Garut. Pendidikan Matematika) (UNY), (Yogyakarta),

lulus tahun (2002); S2 (Bidang Pengajaran (Bandung), lulus tahun (2011).

(ITB), 

e-mosharafa.org

This page is intentionally left blank 